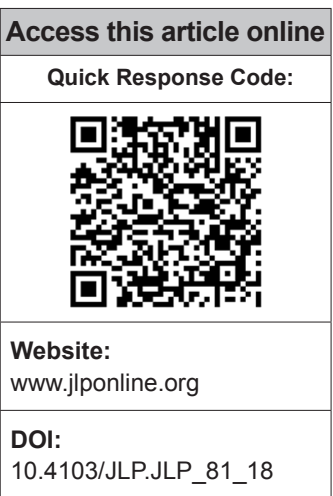

Department of Microbiology, Institute of Medical Sciences, Banaras Hindu University, Varanasi, Uttar Pradesh, India

Address for correspondence: Prof. Ragini Tilak,

Department of Microbiology, Institute of Medical Sciences,

Banaras Hindu

University, Varanasi, Uttar Pradesh, India.

E-mail: raginijain29@ rediffmail.com

Submission: 04-08-2018 Accepted: 16-08-2018

\title{
Extracellular hydrolytic enzyme activities of the different Candida spp. isolated from the blood of the Intensive Care Unit-admitted patients
}

\author{
Nidhi Pandey, Munesh Kumar Gupta, Ragini Tilak
}

\section{Abstract:}

BACKGROUND: Candida spp. secretes various extracellular hydrolytic enzymes. These enzymes are the important virulence factor for the pathogenesis of Candida. We assessed four different enzymatic activities of Candida isolates obtained from bloodstream infections.

MATERIALS AND METHODS: We isolated 79 strains of different Candida species from the blood of the Intensive Care Unit-admitted patients. Species were identified by conventional methods including culture characteristic, germ tube, sugar assimilation, and Dalmau's culture technique. Phospholipase, proteinase, hemolysin, and esterase enzymatic activities were determined by the Plate method.

RESULTS: Non albicans candida were the most common isolates from the blood of the ICU admitted patient with a predominance of Candida tropicalis. Hemolytic activity was the most prominent enzyme activity followed by the proteinase activity. Candida albicans $(89.86 \%)$ was the major proteinase producer, while $95.8 \%$ of $C$. tropicalis produced hemolysin. No esterase activity was shown by the Candida glabrata and Candida krusei.

CONCLUSION: No significant difference was observed between the two most common causative agents of candidemia: $C$. albicans and $C$. tropicalis.

Key words:

Candidemia, esterase, hemolysin, phospholipase, proteinase, virulence factor

\section{Introduction}

andida infections are the leading cause of the morbidity and mortality in the hospitalized patients. ${ }^{[1,2]}$ Candida infections may disseminate hematogenously to the various organs. These disseminated Candida infections usually occur in patients with a history of prolonged antibiotic exposure, immunosuppressive treatment, and patients on parenteral nutrition. ${ }^{[1,3]}$ Different species of Candida are attributed as a cause of these disseminated infections, but four species, namely Candida albicans, Candida tropicalis, Candida parapsilosis, and Candida krusei, account for as much as $95 \%$ of these

This is an open access journal, and articles are distributed under the terms of the Creative Commons Attribution-NonCommercial-ShareAlike 4.0 License, which allows others to remix, tweak, and build upon the work non-commercially, as long as appropriate credit is given and the new creations are licensed under the identical terms.

For reprints contact: reprints@medknow.com infections. ${ }^{[1]}$ Previously, C. albicans was the most common cause of bloodstream fungal infections, but nowadays, non-albicans Candida has superseded the former. ${ }^{[4,5]}$

Candida spp. has grown from successful commensalism to pathogens in various body sites. Candida spp. secrete different extracellular enzymes as phospholipase, protease, and esterase. These hydrolytic enzymes contribute the microbial pathogenicity by accentuating its adhesion, tissue damage, immune system evasion, as well as its dissemination. Hemolysin is another virulence factor that degrades the red blood cells, and iron is released which is taken up by the yeast cells. ${ }^{[6,7]}$ In this study,

\footnotetext{
How to cite this article: Pandey N, Gupta MK, Tilak R. Extracellular hydrolytic enzyme activities of the different Candida spp. isolated from the blood of the Intensive Care Unit-admitted patients. J Lab Physicians 2018;10:392-6.
} 
we have determined the extracellular enzyme activity of the Candida species, isolated from the blood of the Intensive Care Unit (ICU)-admitted patients.

\section{Materials and Methods}

Candida spp. was isolated from the blood of the ICU-admitted patients at a tertiary care center at Sir Sunderlal Hospital, Banaras Hindu University, Varanasi. Candida was identified based on microscopic examination, culture characteristics, germ tube formation, sugar fermentation, sugar assimilation, morphology on cornmeal agar, and color on CHROMagar.

The isolated Candida spp. was screened for the extracellular enzymatic activities, that is, phospholipase, proteinase, hemolysin, and esterase. Phospholipase activity was determined by the method described earlier by Price et al. ${ }^{[8]}$ with little modification done by Costa et al. ${ }^{\left[{ }^{[9]}\right.}$ In this, Sabouraud's dextrose agar (SDA) medium was supplemented with $1 \mathrm{~mol} / \mathrm{L}$ sodium chloride, $0.005 \mathrm{~mol} / \mathrm{L}$ calcium chloride, and $8 \%$ sterile egg yolk suspension. Proteinase activity was determined using the bovine serum albumin agar. ${ }^{[10]}$ Tween 80 opacity medium was used to determine the esterase activity. ${ }^{[10]}$ For hemolysin activity, SDA plates supplemented with $3 \%$ glucose and $7 \%$ sheep blood were used..$^{[11]}$ Ten microliters of a thick suspension of each strain were placed in the center of the plates which were incubated at $37^{\circ} \mathrm{C}$ for 5 days. The test was performed in triplicates. Average value of the colony diameter (a) and the diameter of the colony plus the precipitation zone (b) were measured. The enzyme activity was expressed as Pz value $(a / b)$ as described by Price et al. All enzymatic activity index was classified as follows: $\mathrm{Pz}=1$, negative activity; $0.64<\mathrm{Pz}<0.99$, positive; and $\mathrm{Pz} \leq 0.64$, strongly positive. ${ }^{[6]}$

\section{Results}

A total of 79 strains of Candida spp. were isolated from the blood of the patients, admitted in the ICU. Most of the patients were male with an M:F of 1.82:1. Majority of the Candida spp were isolated from the blood of neonates $(n=41)$, followed by patients below 18 years of age group $(n=16)$ [Table 1]. Out of these 79 isolates, in comparison to $C$. albicans, non-albicans candida $(n=63)$ were predominant. These non-albicans $(n=63)$ were categorized as follows: C. tropicalis $(n=24)$, C. krusei $(n=11), C$. parapsilosis $(n=9)$, Candida glabrata $(n=5)$, and unidentified $(n=14)$ [Table 2].

Extracellular enzyme activities of these isolated Candida spp. were determined by the Plate method. Proteinase, phospholipase, and hemolysin enzymes were produced by most of the Candida species although strains of C. krusei and C. glabrata failed to produce the esterase enzyme [Figure 1]. Hemolysin activity was shown by $89.86 \%$ of the isolated Candida spp., whereas other extracellular enzymes such as proteinase, phospholipase, and esterase were produced only by $84.72 \%, 55.69 \%$, and $37.97 \%$ of the strains, respectively [Table 3 and Figure 2]. Strong proteinase activity was shown by the C. albicans (93.75\%), followed by the C. tropicalis $(87.5 \%)$. Strong hemolytic activity was shown by $95.85 \%$ of the C. tropicalis, followed by the C. albicans $(81.25 \%)$. About $56.25 \%$ of $C$. albicans strains followed by $54.16 \%$ C. tropicalis were strong esterase producers. Only one C. parapsilosis isolate was able to strong esterase producer. No statistical analysis could be performed for esterase activity, as the number of isolates producing esterase enzyme was considerably small. No significant difference between the enzyme production by the $C$. albicans and non-albicans Candida was observed. Similarly, no significant difference was observed between the two most common causes of candidemia, C. albicans, and C. tropicalis [Table 3].

\section{Discussion}

Bloodstream Candida infections in ICU-admitted patients are the life-threatening affliction with an incidence of 0.24-34.3 patients/1000 ICU admissions. ${ }^{[12]}$ These disseminated Candida infections may be dependent on various host defense mechanisms and fungal virulence attributes. These Candida infections are common in the ICU patients, taking parenteral nutrition, prolonged antibiotics, and immunocompromised conditions.

Table 1: Demographic characteristics of patients with bloodstream infection

\begin{tabular}{lc}
\hline Characteristics & Patients (\%) \\
\hline Sex & \\
Male & $51(64.56)$ \\
Female & $28(35.44)$ \\
Age (years) & \\
Neonates & $41(51.89)$ \\
$\leq 1-18$ & $16(20.25)$ \\
$19-35$ & $7(8.86)$ \\
$35-60$ & $9(11.39)$ \\
$\geq 60$ & $7(8.86)$ \\
\hline
\end{tabular}

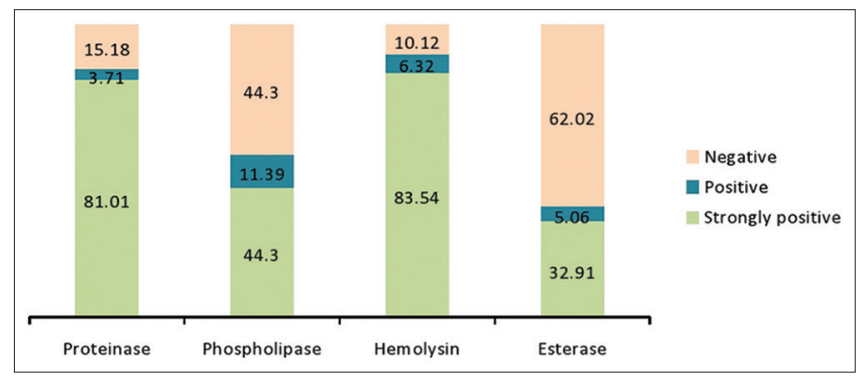

Figure 1: Percentage of Candida strain with extracellular enzyme production 
Table 2: Extracellular enzyme production by Candida spp.

\begin{tabular}{|c|c|c|c|c|c|}
\hline Candida spp. & Degree of variance* & Proteinase & Phospholipase & Hemolysin & Esterase \\
\hline \multirow[t]{3}{*}{ Candida albicans $(n=16)$} & Negative & 0 & 4 & 2 & 7 \\
\hline & Positive & 1 & 3 & 1 & 0 \\
\hline & Strongly positive & 15 & 9 & 13 & 9 \\
\hline \multirow[t]{3}{*}{ Candida tropicalis $(n=24)$} & Negative & 1 & 9 & 1 & 9 \\
\hline & Positive & 2 & 2 & 0 & 2 \\
\hline & Strongly positive & 21 & 13 & 23 & 13 \\
\hline \multirow[t]{3}{*}{ Candida krusei $(n=11)$} & Negative & 4 & 6 & 1 & 11 \\
\hline & Positive & 0 & 0 & 1 & 0 \\
\hline & Strongly positive & 7 & 5 & 9 & 0 \\
\hline \multirow[t]{3}{*}{ Candida parapsilosis $(n=9)$} & Negative & 3 & 5 & 2 & 6 \\
\hline & Positive & 0 & 2 & 2 & 2 \\
\hline & Strongly positive & 6 & 2 & 5 & 1 \\
\hline \multirow[t]{3}{*}{ Candida glabrata $(n=5)$} & Negative & 1 & 2 & 2 & 5 \\
\hline & Positive & 0 & 1 & 0 & 0 \\
\hline & Strongly positive & 4 & 2 & 3 & 0 \\
\hline \multirow[t]{3}{*}{ Others $(n=14)$} & Negative & 3 & 9 & 0 & 11 \\
\hline & Positive & 0 & 1 & 1 & 0 \\
\hline & Strongly positive & 11 & 4 & 13 & 3 \\
\hline
\end{tabular}

Table 3: Distribution of Candida spp. showing different virulence attributes

\begin{tabular}{|c|c|c|c|c|}
\hline Candida spp. & $\begin{array}{l}\text { Virulence } \\
\text { factor }\end{array}$ & Range & Mean & SD \\
\hline \multirow[t]{4}{*}{ Candida albicans $(n=16)$} & Proteinase & $0.2-0.77$ & 0.3025 & 0.1308 \\
\hline & Phospholipase & $0.28-1$ & 0.595625 & 0.3061 \\
\hline & Hemolysin & $0.29-1$ & 0.466875 & 0.2287 \\
\hline & Esterase & $0.18-1$ & 0.670625 & 0.3112 \\
\hline \multirow[t]{4}{*}{ Candida tropicalis $(n=24)$} & Proteinase & $0.18-1$ & 0.349167 & 0.1951 \\
\hline & Phospholipase & $0.26-1$ & 0.629167 & 0.3109 \\
\hline & Hemolysin & $0.2-1$ & 0.3675 & 0.1463 \\
\hline & Esterase & $0.18-1$ & 0.633333 & 0.3231 \\
\hline \multirow[t]{4}{*}{ Candida krusei $(n=11)$} & Proteinase & $0.2-1$ & 0.519 & 0.3823 \\
\hline & Phospholipase & $0.31-1$ & 0.7109 & 0.3334 \\
\hline & Hemolysin & $0.33-1$ & 0.47 & 0.2033 \\
\hline & Esterase & 1 & 1 & 0 \\
\hline \multirow{4}{*}{$\begin{array}{l}\text { Candida parapsilosis } \\
(n=9)\end{array}$} & Proteinase & $0.2-1$ & 0.511111 & 0.3697 \\
\hline & Phospholipase & $0.22-1$ & 0.801111 & 0.297 \\
\hline & Hemolysin & $0.28-1$ & 0.568889 & 0.2954 \\
\hline & Esterase & $0.41-1$ & 0.891111 & 0.2036 \\
\hline \multirow[t]{4}{*}{ Candida glabrata $(n=5)$} & Proteinase & $0.27-1$ & 0.464 & 0.3071 \\
\hline & Phospholipase & $0.28-1$ & 0.696 & 0.36 \\
\hline & Hemolysin & $0.28-1$ & 0.626 & 0.3469 \\
\hline & Esterase & 1 & 1 & 0 \\
\hline \multirow[t]{4}{*}{ Others $(n=14)$} & Proteinase & $0.22-1$ & 0.410714 & 0.3213 \\
\hline & Phospholipase & $0.37-1$ & 0.802143 & 0.287 \\
\hline & Hemolysin & $0.29-1$ & 0.381429 & 0.1081 \\
\hline & Esterase & $0.35-1$ & 0.867143 & 30.2645 \\
\hline
\end{tabular}

$\mathrm{Pz} \leq 0.64$, strongly positive

Previously, C. albicans was considered as the most common cause of bloodstream infection, but in the present study, C. tropicalis outnumber the cases. Similar results of $C$. tropicalis as the most common etiology of Candida infection in ICU patients have been reported by Costa et al. and Chakrabarti et al. ${ }^{[4,12]}$ In comparison

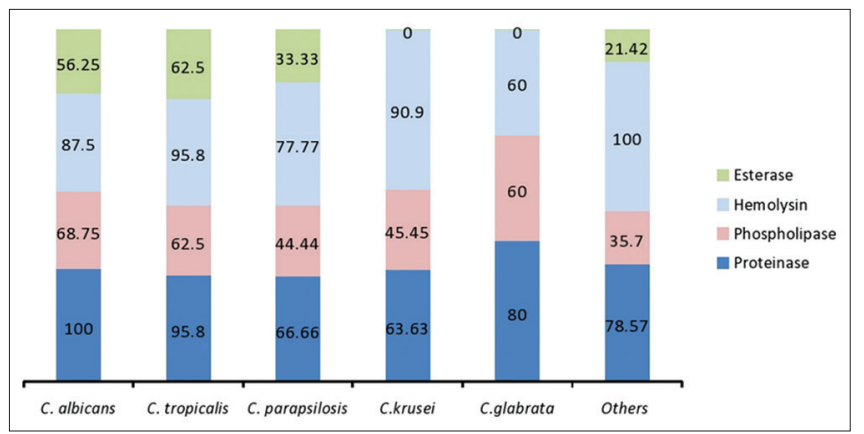

Figure 2: Percentage of extracellular enzymes produced by isolated Candida spp on the basis of score value

to studies performed in European and South American countries, C. parapsilosis is considered as the most common cause of Candida bloodstream infection. This variation may be attributed to the environmental factors, use of central lines, life-supporting devices, and antibiotics usages. In our study, C. tropicalis was the most common isolated Candida followed by the C. albicans $(n=16)$, C. krusei $(n=11)$, and C. parapsilosis $(n=9)$. High C. krusei strains $(n=9)$ isolation may be due to the frequent use of fluconazole either as prophylactic or therapeutic. ${ }^{[13]}$

Candida secretes various extracellular hydrolytic enzymes which act as important virulence factors. ${ }^{[6,2]}$ These hydrolytic enzymes degrade the cellular component of tissues and facilitate their survival, adhesion, invasion, and dissemination. Phospholipase, proteinase, lipase, esterase, hemolysin, etc., are the common hydrolytic enzymes. Phospholipase and proteinase hydrolytic enzymes are considered as the two most common virulence factors as they contribute to the Candida-host interaction. Proteinase enzyme degrades the surface protein and disrupts the local immunity, resulting 
in tissue invasion. Phospholipase enzyme degrades the phospholipid component of the cell membrane, resulting in cell damage and lysis which accentuates its dissemination. In our study, higher phospholipase and proteinase enzyme production was shown by the $C$. albicans strains. Similar results of higher enzyme production have been reported by Canela et al. and Mutlu Sariguzel et al..$^{[6,14]}$ In our study, in comparison to the $C$. tropicalis, phospholipase and proteinase were produced by a higher number of the C. albicans strain, whereas hemolysin and esterase enzymes were produced by a higher number of the $C$. tropicalis strains.

Hemolysin is the enzyme which degrades the cellular component of the blood. This virulence property of Candida spp. helps to acquire iron by degrading hemoglobin from the host and further help pathogen to persist and survive ${ }^{[6,15,16]}$ Hemolysin activity was shown by $95.8 \%$ of C. tropicalis and $90.9 \%$ strains of the C. krusei strains. Only $87.5 \%$ strain of C. albicans produced hemolysin activity. Hemolysin and proteinase enzymes were produced by $>80 \%$ of the isolated Candida spp. Similar results of higher hemolysin production have been reported by Riceto et al. ${ }^{[17]}$ Esterase enzyme is also an important virulence factor which degrades the ester bonds and accentuates its tissue invasion. About $56 \%$ of $C$. albicans showed the esterase activity in comparison to the $C$. tropicalis where only $54 \%$ strain showed the esterase activity. This result is concordant with a study conducted by Kumar et al., where the author reported C. albicans and C. tropicalis species with the highest rate of esterase activity ${ }^{[18]}$ No activity was observed in the isolated strains of the C. glabrata and C. krusei, which are considered as the intrinsic fluconazole resistant. These results are contradictory to the study published by the Fatahinia et al., where they reported the 3+ level esterase activities in C. glabrata isolated from diabetic patients suffering from oral candidiasis. ${ }^{[10]}$ On the other hand, they have also reported C. glabrata as the lowest esterase producer in vulvovaginal candidiasis patients. ${ }^{[19]}$ Although esterase activity was low, yet its mechanism in virulence due to cytotoxic effects in host tissue has been reported by Williams and Lewis ${ }^{[20]}$ In our study, these enzymes were produced by the both common $C$. albicans and $C$. tropicalis $(P>0.05)$ that necessitate the need for search of other factors responsible for their virulence. Our study has a limitation as a considerable number of isolates remain unidentified which needs to be done for proper assessment.

\section{Conclusion}

Non-albicans candida with a preponderance of $C$. tropicalis is the most common isolated yeast from the blood of the ICU-admitted patients. No statistically significant difference for enzymatic activity was observed among the C.albicans and C.tropicalis. Intrinsic fluconazole-resistant C. krusei and C. glabrata failed to produce any esterase activity which needs to be evaluated further.

\section{Acknowledgment}

We are thankful to the Department of Science and Technology for providing fellowship.

\section{Financial support and sponsorship}

Nil.

\section{Conflicts of interest}

There are no conflicts of interest.

\section{References}

1. Giri S, Kindo AJ. A review of Candida species causing bloodstream infection. Indian J Med Microbiol 2012;30:270-8.

2. Tellapragada C, Eshwara VK, Johar R, Shaw T, Malik N, Bhat PV, et al. Antifungal susceptibility patterns, in vitro production of virulence factors, and evaluation of diagnostic modalities for the speciation of pathogenic Candida from bloodstream infections and vulvovaginal candidiasis. J Pathog 2014;2014:142864.

3. Dagi HT, Findik D, Senkeles C, Arslan U. Identification and antifungal susceptibility of Candida species isolated from bloodstream infections in Konya, Turkey. Ann Clin Microbiol Antimicrob 2016;15:36.

4. da Costa VG, Quesada RM, Abe AT, Furlaneto-Maia L, Furlaneto MC. Nosocomial bloodstream Candida infections in a tertiary-care hospital in South Brazil: A 4-year survey. Mycopathologia 2014;178:243-50.

5. Pfaller MA, Diekema DJ. Epidemiology of invasive candidiasis: A persistent public health problem. Clin Microbiol Rev 2007;20:133-63.

6. Canela HM, Cardoso B, Vitali LH, Coelho HC, Martinez R, Ferreira ME. Prevalence, virulence factors and antifungal susceptibility of Candida spp. isolated from bloodstream infections in a tertiary care hospital in Brazil. Mycoses 2018;61:11-21.

7. Mattei AS, Alves SH, Severo CB, Guazzelli Lda S, Oliveira Fde M, Severo LC, et al. Determination of germ tube, phospholipase, and proteinase production by bloodstream isolates of Candida albicans. Rev Soc Bras Med Trop 2013;46:340-2.

8. Price MF, Wilkinson ID, Gentry LO. Plate method for detection of phospholipase activity in Candida albicans. Sabouraudia: Journal of Medical and Veterinary Mycology 198;20:7-14.

9. Costa CR, Passos XS, e Souza LK, Lucena Pde A, Fernandes Ode F, Silva Mdo R, et al. Differences in exoenzyme production and adherence ability of Candida spp. isolates from catheter, blood and oral cavity. Rev Inst Med Trop Sao Paulo 2010;52:139-43.

10. Fatahinia M, Poormohamadi F, Zarei Mahmoudabadi A. Comparative study of esterase and hemolytic activities in clinically important Candida species, isolated from oral cavity of diabetic and non-diabetic individuals. Jundishapur J Microbiol 2015;8:e20893.

11. Sacristán B, Blanco MT, Galán-Ladero MA, Blanco J, Pérez-Giraldo C, Gómez-García AC, et al. Aspartyl proteinase, phospholipase, hemolytic activities and biofilm production of Candida albicans isolated from bronchial aspirates of ICU patients. Med Mycol 2011;49:94-7.

12. Chakrabarti A, Sood P, RudramurthySM,ChenS,KaurH,Capoor M, 
et al. Incidence, characteristics and outcome of ICU-acquired candidemia in India. Intensive Care Med 2015;41:285-95.

13. Oberoi JK, Wattal C, Goel N, Raveendran R, Datta S, Prasad K, et al. Non-albicans Candida species in blood stream infections in a tertiary care hospital at New Delhi, India. Indian J Med Res 2012;136:997-1003.

14. Mutlu Sariguzel F, Berk E, Koc AN, Sav H, Demir G. Investigation of the relationship between virulence factors and genotype of Candida spp. isolated from blood cultures. J Infect Dev Ctries 2015;9:857-64.

15. Rossoni RD, Barbosa JO, Vilela SF, Jorge AO, Junqueira JC. Comparison of the hemolytic activity between C. albicans and non-albicans Candida species. Braz Oral Res 2013;27:484-9.

16. Wan L, Luo G, Lu H, Xuan D, Cao H, Zhang J, et al. Changes in the hemolytic activity of Candida species by common electrolytes. BMC Microbiol 2015;15:171.

17. Riceto ÉB, Menezes Rde P, Penatti MP, Pedroso Rdos S. Enzymatic and hemolytic activity in different Candida species. Rev Iberoam Micol 2015;32:79-82.

18. Kumar CP, Menon T, Sundararajan T, Nalini S, Thirunarayan MA, Rajasekaran S, et al. Esterase activity of Candida species isolated from immunocompromised hosts. Rev Iberoam Micol 2006;23:101-3.

19. Fatahinia M, Halvaeezadeh M, Rezaei-Matehkolaei A. Comparison of enzymatic activities in different Candida species isolated from women with vulvovaginitis. J Mycol Med 2017;27:188-94.

20. Williams D, Lewis M. Pathogenesis and treatment of oral candidosis. Journal of Oral Microbiology 2011;3:5771. 